\title{
Are COVID-19 vaccines safe for people with epilepsy? A cross-sectional study
}

\author{
Hüseyin Nezih Özdemir ${ }^{1}\left[\right.$ D Birgül Dere ${ }^{2} \cdot$ Figen Gökçay $^{2} \cdot$ Ahmet Gökçay $^{2}$
}

Received: 10 January 2022 / Accepted: 11 February 2022 / Published online: 27 February 2022

(c) Fondazione Società Italiana di Neurologia 2022

\begin{abstract}
Background COVID-19 disease was first seen in December 2019 and was declared a pandemic soon after. To fight the pandemic, there is an immense need for effective vaccines. The purposes of our study were to investigate the effect of coronavirus vaccines on seizures in people with epilepsy (PWE) and assess the adverse events of COVID-19 vaccine in PWE.

Methods This was a cross-sectional study. We included epilepsy patients who got vaccinated with two or three doses at least 1 month earlier. We gathered the data using a standardized form. The form contained questions about patients' demographic features, clinical features, and information about the vaccination and its adverse events. The questionnaire included questions about epilepsy-related adverse events.

Results We included 178 people with epilepsy in our study. The frequency of adverse events was lower than clinical studies of the vaccines. The mean number of seizures in the month before the vaccination was 1.62, between the doses was 1.61, and after vaccination was 1.64 . There was no significant difference in the number of monthly seizures before the vaccination, the month between the doses, or the month after the vaccination $(p=0.46)$.

Conclusions The vaccines under consideration in our study were tolerated well by the epilepsy patients. The vaccines did not affect the monthly number of seizures of the PWE. A small number of patients had more seizures than normal after vaccination. We think that benefits of the vaccines outweigh the slightly increased possibility of having a seizure after vaccination.
\end{abstract}

Keywords Epilepsy $\cdot$ COVID-19 $\cdot$ Vaccine $\cdot$ Safety

\section{Introduction}

Severe acute respiratory syndrome coronavirus 2 (SARS$\mathrm{CoV}-2$ ) is a contagious virus responsible for COVID-19 disease [1]. COVID-19 disease was first seen in December 2019 and was declared a pandemic soon after [1]. The pandemic affected people worldwide and caused millions of deaths [1]. To fight the pandemic, there is an immense need for effective vaccines [2].

Several COVID-19 vaccines with different mechanisms of action are in use nowadays, and several potential vaccines are in the development phases [2]. Since COVID-19 vaccines have been employed only recently, there is a lack of

Hüseyin Nezih Özdemir

huseyinnezihozdemir@gmail.com

1 Department of Neurology, Necip Fazıl City Hospital, 46050 Kahramanmaraş, Turkey

2 Department of Neurology, Ege University Medical School, 35100 İzmir, Turkey experience in using them in patients with chronic diseases such as epilepsy [3].

Epilepsy is one of the most common chronic neurological disorders [4]. Clinical trials of the COVID-19 vaccines showed no severe neurological adverse event [5-7]. Furthermore, studies on other vaccines found that vaccination did not cause an increase in seizure risk except for the diphtheria, tetanus, and pertussis (DTP) vaccine and the measles, mumps, and rubella (MMR) vaccine [8]. However, real-life experience on this subject remains lacking.

The CoronaVac inactivated whole-virion vaccine and the Pfizer-BioNTech mRNA vaccine (BNT162b2) were licensed in Turkey for people aged over 15 years old [9]. The vaccines are administrated in two doses separated by a 4-week interval [9]. People may have a third vaccine dose if they wish to [9]. People can choose either vaccine regardless of the vaccine they got fully vaccinated for the third dose, and, in this case, they can be vaccinated with different vaccines [9]. By November 2021, more than 118 million doses had been administered in Turkey [9]. 
The purposes of our study were to investigate the effect of coronavirus vaccines on seizures in people with epilepsy (PWE) and assess the adverse events of COVID-19 vaccine in PWE. We aim to share our real-life experience on this subject.

\section{Methods}

This was a cross-sectional study. The study was conducted in Ege University Hospital, Department of Neurology. Ege University Hospital is a tertiary center in Turkey. Approximately five hundred PWEs are followed up regularly in Ege University Hospital, Department of Neurology. PWEs who presented to our tertiary center between January 7 , 2021, and January 9, 2021, were evaluated for the study. We included those who met the following criteria: having a definite diagnosis of epilepsy according to the International League Against Epilepsy (ILAE) Guideline, being older than 18 years old, being vaccinated with two or three doses at least 1 month earlier, and having a follow-up of at least 3 months [10]. Patients who had unconfirmed epilepsy diagnosis according to the ILAE Guideline, PWEs diagnosed with epilepsy less than 3 months ago, PWEs who do not visit the outpatient clinic regularly, PWEs with low drug compliance, PWEs with additional psychogenic nonepileptic seizures, and PWEs with severe comorbid diseases which can interfere the result were excluded.

We gathered the data using a standardized form. The form contained questions about patients' demographic features, clinical features, and information about the vaccination and its adverse events. Patients' demographic features including age, sex, and age at onset of epilepsy were asked. Patients' seizures were classified according to the ILAE Classification of Epilepsies 2017 Guideline [10]. Patients' most recent electroencephalography and magnetic resonance imaging findings were noted.

The following information about vaccination and vaccine-related systemic adverse events were recorded: vaccination date, vaccine type, vaccine-related adverse events after each dose, injection site redness or pain, fever $\left(>38^{\circ} \mathrm{C}\right.$ temperature), tiredness, headache, muscle pain, and chills. Serious adverse events were also questioned. The World Health Organization defined serious adverse events as the following: results in death, hospitalization, or compelling or persistent disability [11]. The patients' COVID-19 infection history was noted. Patients who had the history of detection of SARS-CoV-2 by molecular methods were assed as PWEs with positive COVID-19 infection history.

The patients were questioned about the frequency of seizures in the month before vaccination, yearly frequency of seizures, and the types and doses of medication they were on at that time. The vaccination dates and type of vaccine were noted. The questionnaire included questions about epilepsy-related adverse events: having more seizures in the first week after vaccination, frequency of seizures between the two doses, frequency of seizures in the month after the second and third doses, new-onset status epilepticus, and new seizure type. We utilized patients' seizure diaries to ascertain monthly seizure frequency. The seizures were recorded by PWEs in epilepsy diaries.

We divided the patients into three subgroups according to seizure frequency: seizure-free, lower seizure frequency, and higher seizure frequency. We used a Seizurebased Outcome Classification System (Duke) for this grouping [12]. Seizure-free was considered as freedom from all types of seizures for 12 months or three times the pre-intervention inter-seizure interval [13]. Moreover, the PWEs were divided into five groups according to age at onset of epilepsy. The age groups were determined in line with the milestones of the life span: infancy and toddlerhood $0-2$ years, childhood $2-12$ years, adolescence $12-18$, adulthood $18-65$, and late adulthood $>65$ years of age. We compared these subgroups for vaccine-related adverse events. To assess the change in seizure frequency, we statistically compared the patients' monthly seizure frequencies before the vaccination, the month between the doses, and the month after vaccination. We completed the form for the mentally disabled patients with their caregivers.

The Local Ethical Committee of Ege University Medical School approved the study. Written informed consent was obtained from all participants.

\section{Statistical analysis}

The data were analyzed using SPSS version 25. Numeric variables, with a normal distribution, were defined with means and standard deviations, and those without a normal distribution were defined with median values. The Shapiro-Wilk test was used to test for normality of distribution. When comparing quantitative data to determine whether there was a difference between the groups, Student's $t$-test was used for data with a normal distribution and the Mann-Whitney $U$ test for data without a normal distribution. To determine the differences between groups, the $\chi^{2}$ and Fisher's exact test were used. The relations of numerical variables with each other were evaluated with Pearson correlation analysis for those with a normal distribution and Spearman's correlation analysis for those without one. The Friedman test was used to evaluate whether there were any statistically significant differences between the distributions of three or more paired groups. Values of $p<0.05$ were considered statistically significant. 


\section{Results}

In the abovementioned time span, 312 PWEs visited the outpatient clinic. We included 178 PWEs according to the inclusion criteria. While 91 PWEs $(51.1 \%)$ were female, 87 PWEs (48.9\%) were male. The mean age of the study population was 32.47 years $(S D=12.76)$. The median follow-up duration was 8 years (minimum $=0.5$ years, maximum $=42$ years). Only eight patients were older than 55 years old.

The number of the PWE who had epilepsy onset in infancy and toddlerhood was $23(12.9 \%)$, in childhood was $54(30.3 \%)$, in adolescence was $34(19.1 \%)$, in adulthood was $64(35.9 \%)$, and in late adulthood was $3(1.8 \%)$. The majority of the PWEs in our study group had generalized epilepsy; 111 PWEs (62.3\%) had generalized epilepsy, 27 PWEs (15.2\%) had focal epilepsy, and 40 PWEs (22.5\%) had combined epilepsy.

Seventy-four PWEs (41.6\%) had abnormal EEG findings. In line with the distribution of the types of epilepsy in our study group, generalized epileptiform activity was the most frequent EEG abnormality, followed by focal epileptiform activity. Forty-seven PWEs (26.4\%) had generalized epileptiform activity and 14 PWEs (7.9\%) had focal epileptiform activity. Eight PWEs (4.5\%) showed focal and generalized epileptiform activity on different EEG traces. Four PWEs (2.3\%) showed basic rhythm slowing and $1(0.6 \%)$ showed a brush rhythm on EEG.

One hundred five participants (59\%) were seizure-free. Thirty-four patients (19.1\%) were grouped in the lower seizure frequency group, while 39 patients $(21.9 \%)$ were grouped in the higher seizure frequency group. The mean number of seizures in the month before the vaccination was 1.62 , between the doses was 1.61 , and after vaccination was 1.64 . There was not a statistically significant difference among the monthly number of seizures $(p=0.46)$. Only one patient $(0.6 \%)$ was not on any anti-seizure medication (ASM). While 78 PWEs (43.8\%) were on monotherapy, 99 PWEs (55.6\%) were on polytherapy. The patients' clinical and demographic features are shown in Table 1.

Table 1 Patients' clinical and demographic features

\begin{tabular}{|c|c|c|c|c|}
\hline & $\mathrm{BNT} 162 \mathrm{~b} 2(n=136)$ & CoronaVac $(n=35)$ & Combination $(n=7)$ & Total $(n=178)$ \\
\hline \multicolumn{5}{|l|}{ Gender } \\
\hline Female & $64(35.9 \%)$ & $22(12.4 \%)$ & $5(2.8 \%)$ & $91(51.1 \%)$ \\
\hline Male & $72(40.4 \%)$ & $13(7.3 \%)$ & $2(1.1 \%)$ & $87(48.9 \%)$ \\
\hline \multicolumn{5}{|l|}{ Age (years), } \\
\hline Median (range) & $27(18-55)$ & $33(18-81)$ & $46(23-69)$ & $29(18-81)$ \\
\hline \multicolumn{5}{|l|}{ Epilepsy type } \\
\hline Focal epilepsy & $16(8.9 \%)$ & $9(5.1 \%)$ & $2(1.1 \%)$ & $27(15.2 \%)$ \\
\hline Generalized epilepsy & $91(51.1 \%)$ & $17(9.6 \%)$ & $3(1.7 \%)$ & $111(62.3 \%)$ \\
\hline Combined epilepsy & $29(16.3 \%)$ & $9(5.1 \%)$ & $2(1.1 \%)$ & $40(22.5 \%)$ \\
\hline \multicolumn{5}{|l|}{ Age at onset of epilepsy } \\
\hline $0-2$ years & $16(8.9 \%)$ & $7(3.9 \%)$ & 0 & $23(12.9 \%)$ \\
\hline $2-12$ years & $46(25.9 \%)$ & $7(3.9 \%)$ & $1(0.6 \%)$ & $54(30.3 \%)$ \\
\hline $12-18$ years & $28(15.7 \%)$ & $4(2.2 \%)$ & $2(1.1 \%)$ & $34(19.1 \%)$ \\
\hline $18-65$ years & $46(25.9 \%)$ & $15(8.4 \%)$ & $3(1.8 \%)$ & $64(35.9 \%)$ \\
\hline$>65$ years & 0 & $2(1.1 \%)$ & $1(0.6 \%)$ & $3(1.8 \%)$ \\
\hline \multicolumn{5}{|l|}{ EEG abnormality } \\
\hline Yes & $55(30.9 \%)$ & $16(8.9 \%)$ & $3(1.7 \%)$ & $74(41.6 \%)$ \\
\hline No & $81(45.5 \%)$ & $19(10.7 \%)$ & $4(2.2 \%)$ & $104(58.4 \%)$ \\
\hline \multicolumn{5}{|l|}{ Seizure frequency } \\
\hline Seizure-free & $82(46.1 \%)$ & $17(9.6 \%)$ & $6(3.4 \%)$ & $105(59 \%)$ \\
\hline Lower seizure frequency & $29(16.3 \%)$ & $4(2.2 \%)$ & $1(0.6 \%)$ & $34(19.1 \%)$ \\
\hline Higher seizure frequency & $25(14.1 \%)$ & $14(7.8 \%)$ & 0 & $39(21.9 \%)$ \\
\hline \multicolumn{5}{|l|}{ Number of ASMs } \\
\hline On no medication & $1(0.6 \%)$ & 0 & 0 & $1(0.6 \%)$ \\
\hline One drug & $57(32.1 \%)$ & $15(8.4 \%)$ & $6(3.4 \%)$ & $78(43.8 \%)$ \\
\hline Two drugs & $43(24.2 \%)$ & $8(4.4 \%)$ & $1(0.6 \%)$ & $52(29.2 \%)$ \\
\hline Three drugs & $32(17.9 \%)$ & $10(5.6 \%)$ & 0 & $42(23.6 \%)$ \\
\hline Four or more drugs & $3(1.7 \%)$ & $2(1.1 \%)$ & 0 & $5(2.8 \%)$ \\
\hline \multicolumn{5}{|c|}{ Number of seizures in the month before vaccination } \\
\hline Mean $(S D)$ & $1.12(3.5)$ & $3.91(7.37)$ & 0 & $1.62(4.59)$ \\
\hline
\end{tabular}


One hundred thirty-six PWEs (76.4\%) were vaccinated with two doses of BNT162b2, 35 PWEs (19.7\%) with two doses of CoronaVac, and 7 PWEs (3.9\%) with a combination of the vaccines (one dose of BNT162b2 following two doses of CoronaVac). Eight PWEs (4.5\%) had had COVID19 infection before being vaccinated with CoronaVac.

Fifty-two PWEs (29.2\%) had a local adverse event (injection site redness/pain) after the first dose of the vaccine. Forty-nine of the 136 (36\%) PWEs vaccinated with BNT162b2 and 3 of the $42(7.1 \%)$ PWEs who received Corona Vac had a local adverse event. Having a local adverse event is significantly more frequent with BNT162b2 $(p=0.003)$. Fifty-eight PWEs $(32.6 \%)$ had at least one

Table 2 The frequency of adverse events after the first dose of vaccines

\begin{tabular}{|c|c|c|c|}
\hline & BNT162b2 $(n=136)$ & CoronaVac $(n=42)$ & $p$ \\
\hline \multicolumn{4}{|c|}{ Local adverse effects } \\
\hline $\begin{array}{l}\text { Injection } \\
\text { site red- } \\
\text { ness/pain }\end{array}$ & $49(36 \%)$ & $3(7.1 \%)$ & $0.003 *$ \\
\hline \multicolumn{4}{|c|}{ General adverse effects } \\
\hline Fatigue & $25(18.3 \%)$ & $4(9.5 \%)$ & 0.17 \\
\hline Headache & $19(13.9 \%)$ & $5(11.9 \%)$ & 0.73 \\
\hline Fever & $16(11.7 \%)$ & $3(7.1 \%)$ & 0.39 \\
\hline Myalgia & $11(8 \%)$ & $2(4.7 \%)$ & 0.46 \\
\hline Chills & $9(6.6 \%)$ & $3(7.1 \%)$ & 0.90 \\
\hline Nausea & $2(1.4 \%)$ & $1(2.3 \%)$ & 0.68 \\
\hline Dizziness & $2(1.4 \%)$ & $2(4.7 \%)$ & 0.20 \\
\hline Diarrhea & $2(1.4 \%)$ & $1(2.3 \%)$ & 0.68 \\
\hline
\end{tabular}

systemic adverse event after the first dose of the vaccine. There was not a significant difference for having a systemic adverse event (36\% vs. $21.4 \%$ ) between the BNT162b2 and CoronaVac groups $(p=0.07)$. Detailed information about systemic adverse events is provided in Table 2. No severe adverse events were reported after the first dose of the vaccines.

We compared the clinical features of the PWE who had at least one adverse event and had no adverse event (Table 3 ). Epilepsy type and age at onset of epilepsy were not associated with local adverse events ( $p=0.19$ and $p=0.44$, respectively). The number of drugs to treat epilepsy and seizure frequency were not related to the presence of local adverse events ( $p=0.33$ and $p=0.59$, respectively). Moreover, having a systemic adverse event after the first dose of the vaccine was not associated with any of the clinical features of the PWE. Epilepsy type, age at onset of epilepsy, number of drugs to treat epilepsy, and seizure frequency were not associated with having systemic adverse events $(p=0.72$, $p=0.24, p=0.16$ and $p=0.25$, respectively).

Forty-three PWEs (24.1\%) had a local adverse event after the second dose of the vaccine. The presence of a local adverse event was significantly more common in the BNT162b2 group than in the CoronaVac group (30.1\% vs. $4.7 \%, p=0.001)$. Forty-six PWEs $(25.8 \%)$ had at least one systemic adverse event. There was no significant difference between the frequency of systemic adverse events between the BNT162b2 group and the CoronaVac group (28.6\% vs. $16.6 \%, p=0.12$ ). The systemic adverse events after the
Table 3 The association between patients' clinical features and adverse events after the first dose of vaccines

\begin{tabular}{|c|c|c|c|c|}
\hline & $\begin{array}{l}\text { Patient-reported local } \\
\text { adverse effect } \\
\text { Present Absent } \\
N(\%) N(\%)\end{array}$ & $p$ & $\begin{array}{l}\text { Patient-reported general } \\
\text { adverse effect } \\
\text { Present Absent } \\
N(\%) N(\%)\end{array}$ & $p$ \\
\hline \multicolumn{5}{|l|}{ Epilepsy type } \\
\hline $\begin{array}{l}\text { Focal epilepsy } \\
\text { Generalized epilepsy } \\
\text { Combined epilepsy }\end{array}$ & $\begin{array}{l}6(22.2) 21(77.8) \\
38(34.2) 73(65.8) \\
8(20) 32(80)\end{array}$ & 0.19 & $\begin{array}{l}7(25.9) 20(70.1) \\
37(33.3) 74(66.7) \\
14(35) 26(65)\end{array}$ & 0.72 \\
\hline \multicolumn{5}{|l|}{ Age at onset of epilepsy } \\
\hline $\begin{array}{l}0-2 \text { years } \\
2-12 \text { years } \\
12-18 \text { years } \\
18-65 \text { years } \\
>65 \text { years }\end{array}$ & $\begin{array}{l}6(26.1) 17(73.9) \\
16(29.6) 38(70.4) \\
14(41.2) 20(58.8) \\
16(25) 48(75) \\
0(0) 3(100)\end{array}$ & 0.44 & $\begin{array}{l}8(34.8) 15(62.2) \\
17(31.5) 37(68.5) \\
16(47.1) 18(52.9) \\
17(26.6) 47(73.4) \\
0(0) 3(100)\end{array}$ & 0.24 \\
\hline \multicolumn{5}{|l|}{ Seizure frequency } \\
\hline $\begin{array}{l}\text { Seizure-free } \\
\text { Lower seizure frequency } \\
\text { Higher seizure frequency }\end{array}$ & $\begin{array}{l}28(26.7) 77(73.3) \\
12(35.3) 22(64.7) \\
12(30.8) 27(67.9)\end{array}$ & 0.59 & $\begin{array}{l}30(28.6) 75(74.2) \\
15(44.1) 19(55.9) \\
13(33.3) 26(66.7)\end{array}$ & 0.25 \\
\hline \multicolumn{5}{|l|}{ Number of ASMs } \\
\hline $\begin{array}{l}\text { No medication } \\
\text { Monotherapy } \\
\text { Polytherapy }\end{array}$ & $\begin{array}{l}1(100) 0 \\
26(33.3) 52(66.7) \\
25(25.3) 74(74.7)\end{array}$ & 0.33 & $\begin{array}{l}1(100) 0(0) \\
25(32.1) 53(67.9) \\
32(32.3) 67(67.7)\end{array}$ & 0.18 \\
\hline
\end{tabular}

$A S M$ anti-seizure medication 
second dose are shown in Table 4. No serious adverse events were recorded after the second dose of the vaccines.

The clinical characteristics of the PWE did not affect the frequency of the adverse events after the second vaccination dose. Epilepsy type, age at onset of epilepsy, number of drugs to treat epilepsy, and seizure frequency were not associated with having a local adverse event $(p=0.84$, $p=0.83, p=0.90$, and $p=0.08$, respectively) or systemic adverse events $(p=0.70, p=0.66, p=0.54$, and $p=0.64$, respectively) (Table 5).

We compared the monthly number of seizures. The mean number of seizures in the month before the vaccination was 1.62 , between the doses was 1.61 , and after vaccination was

Table 4 The frequency of adverse effects after the second dose of vaccines

\begin{tabular}{|c|c|c|c|}
\hline & BNT162b2 $(n=136)$ & CoronaVac $(n=42)$ & $p$ \\
\hline \multicolumn{4}{|c|}{ Local adverse effects } \\
\hline $\begin{array}{l}\text { Injection } \\
\text { site red- } \\
\text { ness/pain }\end{array}$ & $41(30.1 \%)$ & $2(4.7 \%)$ & 0.001* \\
\hline \multicolumn{4}{|c|}{ General adverse effects } \\
\hline Fatigue & $16(11.7 \%)$ & $3(7.1 \%)$ & 0.39 \\
\hline Headache & $17(12.5 \%)$ & $4(9.5 \%)$ & 0.60 \\
\hline Fever & $10(7.3 \%)$ & $1(2.3 \%)$ & 0.24 \\
\hline Myalgia & $11(8 \%)$ & $2(4.7 \%)$ & 0.46 \\
\hline Chills & $7(5.1 \%)$ & $2(4.7 \%)$ & 0.92 \\
\hline Nausea & $2(1.4 \%)$ & $1(2.3 \%)$ & 0.68 \\
\hline Dizziness & $3(2.2 \%)$ & $1(2.3 \%)$ & 0.94 \\
\hline Diarrhea & 1 & 0 & \\
\hline
\end{tabular}

1.64. There was no significant difference in the number of monthly seizures before the vaccination, the month between the doses, or the month after the vaccination $(p=0.46)$. Seven patients were vaccinated with a combination of vaccines ( 2 doses of CoronaVac and one dose of BNT162b2). These seven patients were seizure-free and vaccination did not trigger any seizure. Eight patients had caught the COVID-19 infection before the vaccination. Four patients were in the seizure-free group, two patients were in the lower seizure frequency group, and two patients were in the higher seizure frequency group. Two PWEs in the higher seizure frequency group had seizures (one seizure per month). This may be expected since they were in a higher seizure frequency group.

Only four PWEs had more seizures than normal for patients. Three patients were male and one patient was female. All patients were younger than 40 years of age. They had had epilepsy for more than 10 years. All patients were on polytherapy. Three patients were vaccinated with BNT162b2 and one patient was vaccinated with CoronaVac. Seizures occurred within the first two days after the first dose of vaccine. It is important to emphasize that all patients had systemic adverse events, especially fever and seizures that occurred in the first two days after vaccination. One patient (patient 3 in Table 6) had two additional seizures after vaccination, and the remaining three patients had one additional seizure. No patient had status epilepticus. No adjustment of ASMs was made. Detailed information is provided in Table 6.
Table 5 The association between patients' clinical features and side effects after the second dose of vaccines

\begin{tabular}{|c|c|c|c|c|}
\hline & $\begin{array}{l}\text { Patient-reported local } \\
\text { adverse effect } \\
\text { Present Absent } \\
\text { N }(\%) \mathrm{N}(\%)\end{array}$ & $\mathrm{p}$ & $\begin{array}{l}\text { Patient-reported general } \\
\text { adverse effect } \\
\text { Present Absent } \\
\text { N (\%) N (\%) }\end{array}$ & $\mathrm{p}$ \\
\hline \multicolumn{5}{|l|}{ Epilepsy type } \\
\hline $\begin{array}{l}\text { Focal epilepsy } \\
\text { Generalized epilepsy } \\
\text { Combined epilepsy }\end{array}$ & $\begin{array}{l}5(18.5) 22(81.5) \\
28(25.2) 83(74.8) \\
10(25) 30(75)\end{array}$ & 0.84 & $\begin{array}{l}5(18.5) 22(81.5) \\
30(27.1) 81(72.9) \\
11(27.5) 29(72.5)\end{array}$ & 0.70 \\
\hline \multicolumn{5}{|l|}{ Age at onset of epilepsy } \\
\hline $\begin{array}{l}0-2 \text { years } \\
2-12 \text { years } \\
12-18 \text { years } \\
18-65 \text { years } \\
>65 \text { years }\end{array}$ & $\begin{array}{l}4(17.4) 19(82.6) \\
13(24.1) 41(75.9) \\
10(29.4) 24(70.6) \\
16(25) 48(75) \\
0(0) 3(100)\end{array}$ & 0.83 & $\begin{array}{l}5(21.7) 18(72.3) \\
17(31.4) 37(68.6) \\
10(29.4) 24(70.6) \\
14(21.9) 50(78.1) \\
0(0) 3(100)\end{array}$ & 0.66 \\
\hline \multicolumn{5}{|l|}{ Seizure frequency } \\
\hline $\begin{array}{l}\text { Seizure-free } \\
\text { Lower seizure frequency } \\
\text { Higher seizure frequency }\end{array}$ & $\begin{array}{l}25(23.8) 80(76.2) \\
9(26.4) 25(73.6) \\
9(23.1) 30(76.9)\end{array}$ & 0.94 & $\begin{array}{l}24(22.9) 81(77.1) \\
10(29.4) 24(70.6) \\
12(30.8) 27(69.2)\end{array}$ & 0.54 \\
\hline \multicolumn{5}{|l|}{ Number of ASMs } \\
\hline $\begin{array}{l}\text { No medication } \\
\text { Monotherapy } \\
\text { Polytherapy }\end{array}$ & $\begin{array}{l}1(100) 0(0) \\
19(24.4) 59(76.6) \\
23(22.4) 76(77.6)\end{array}$ & 0.08 & $\begin{array}{l}1(100) 0(0) \\
19(24.4) 59(76.6) \\
26(25.5) 73(74.5)\end{array}$ & 0.64 \\
\hline
\end{tabular}

$A S M$ anti-seizure medication 
Table 6 Demographic and clinical features of patients who had more seizures than usual

\begin{tabular}{|c|c|c|c|c|c|c|c|c|}
\hline & Age (years) & Gender & $\begin{array}{l}\text { Epilepsy } \\
\text { duration } \\
\text { (years) }\end{array}$ & Vaccine/dose & Seizure type & Epilepsy type & $\begin{array}{l}\text { Number } \\
\text { of ASMs }\end{array}$ & $\begin{array}{l}\text { Accompa- } \\
\text { nying side } \\
\text { effects }\end{array}$ \\
\hline Patient 1 & 21 & Male & 10 & CoronaVac/first & Generalized motor seizure & Generalized epilepsy & 3 & $\begin{array}{l}\text { Fever } \\
\text { Myalgia } \\
\text { Fatigue }\end{array}$ \\
\hline Patient 2 & 32 & Male & 14 & BNT162b2/first & Generalized motor seizure & Combined epilepsy & 2 & $\begin{array}{l}\text { Fever } \\
\text { Fatigue }\end{array}$ \\
\hline Patient 3 & 18 & Female & 10 & BNT162b2/first & $\begin{array}{l}\text { Focal seizure with impaired } \\
\text { awareness }\end{array}$ & Combined epilepsy & 3 & Fever \\
\hline Patient 4 & 35 & Male & 19 & BNT162b2/first & $\begin{array}{l}\text { Focal seizure with impaired } \\
\text { awareness }\end{array}$ & Combined epilepsy & 3 & Fever \\
\hline
\end{tabular}

ASM anti-seizure medication

\section{Discussion}

This cross-sectional study shows real-life data from our tertiary epilepsy clinic. The mean age of our patients was 32.47 years $(S D=12.76)$. It is lower than that of European peers, which was $47.9(S D=20.1)$ in a tertiary center in Germany and $48.2(S D=19.8)$ in a tertiary center in Spain [14, 15]. The demographic structure of the Turkish population can explain this difference. According to the Turkish Statistical Institute's official data, the proportion of the youth population in Turkey is the highest in Europe [16].

Epilepsy started in adulthood in $35.9 \%$ of the patients and late adulthood in $1.8 \%$. Our statistics were similar to those of a multicenter study from France [17]. The majority of the patients in our study sample had generalized epilepsy. The distribution of epilepsy types may vary among centers [3, $14,15]$. The drug-resistant epilepsy rate was $19.1 \%$ in our patients, similar to the literature rates [18]. We evaluated the clinical features of our patients in accordance with the literature.

The rate of local adverse events was $36 \%$ after the first dose of BNT162b2 and 30.1\% after the second dose of it. The incidence of local adverse events was lower than that of the clinical trials (83\% after the first dose; $78 \%$ after the second dose) and a UK community-based observational study $(71.9 \%$ after the first dose; $68.5 \%$ after the second dose) $[5,19]$.

The local adverse events were significantly more frequent in patients that had received BNT162b2 than in patients that had received CoronaVac for the first and second doses ( $p=0.003$ and $p=0.001$, respectively). In the clinical trials of the vaccines, local adverse events occurred much more frequently in patients vaccinated with BNT162b2 (83\% after the first dose; $78 \%$ after the second dose) than in those vaccinated with CoronaVac $(2.7 \%$ overall) $[5,6]$. The frequency of local adverse events after combined vaccines was $28.6 \%$, similar to the frequency of adverse events after the first dose of BNT162b2. A CombiVacS study found a similar adverse event profile with BNT162b2 following the ChAdOx1-S vaccine [20]. To the best of our knowledge, there are no data in the literature about the adverse event profile of BNT162b2 following CoronaVac.

There was no significant difference between the frequency of systemic adverse events between the BNT162b2 group and the CoronaVac group $(p=0.07$ and $p=0.12$, respectively). Our study's rate of having a systemic adverse event is lower than that of the clinical trial of the vaccines and community-based studies [5, 6, 19]. A cross-sectional study conducted with PWE in Germany found a rate of having a systemic adverse event of 33\% [14]. In our study, the patients were questioned retrospectively about adverse events; recall bias can explain the difference for both local adverse events and systemic adverse events.

In our study, the most commonly reported adverse events were fatigue and headache for BNT162b2 and CoronaVac. Clinical trials showed that fatigue and headache were the most common systemic adverse events for BNT162b2 and CoronaVac [5, 6]. A real-life study from Czechia also found fatigue and headache as the most common adverse events [21]. The less prevalent adverse events in our study, such as fever, myalgia, and chills, were also less prevalent in the clinical and cross-sectional studies [5, 6, 21]. Almost all participants' local adverse events and systemic adverse events lasted less than 7 days, as the clinical trials and real-life studies stated $[3,5,6]$.

The clinical trials showed that serious adverse advents are infrequent with BNT162b2 and CoronaVac [5, 6]. The incidence of serious adverse events was $0.1 \%$ for both vaccines and no patient reported serious adverse events in our study.

We investigated the association between patients' clinical characteristics and having a vaccine adverse event. Our study did not find that any of the patients' epilepsy characteristics, including epilepsy type, age at onset of epilepsy, seizure frequency, and the number of ASMs patients were 
using, were associated with having a vaccine-related adverse event. Von Wrede et al. indicated that having an earlier onset of epilepsy and using a lower number of ASMs can predict having a vaccine adverse event $83.3 \%$ correctly [14]. In contrast to a German study, Massoud et al. did not find an association between epilepsy duration and having a vaccinerelated adverse event [3]. Moreover, Massoud et al. stated that receiving polytherapy was associated with a higher frequency of vaccine-related adverse events [3]. Since there are contrasting results in the literature, the relationship between the PWE's clinical characteristics and vaccine-related adverse events needs to be interpreted cautiously. Clinical trials showed that the vaccines under consideration in our study are safe for people with chronic diseases $[5,6]$. Our data suggested no association between the PWE's clinical characteristics and adverse events [23]. We need more information to define an association between epilepsy treatment and having a systemic adverse event.

The vaccines under consideration did not affect the monthly number of seizures in our study. Vaccination is recommended for PWE [8]. Moreover, the ILAE specifically recommends vaccination against COVID-19 infection for PWE [22]. An elevated seizure risk was found only for the DTP vaccine and the MMR vaccine in the first three days after vaccination $[8,23]$. It was hypothesized that fever caused by vaccination might trigger seizures [8, 23]. Fever can also trigger seizures in adults [24]. Fever presented as a systemic adverse event in all of our patients who had more seizures than normal after vaccination. Triggered seizures often occur in the first three days after vaccination $[3,8$, 23]. Longer duration of epilepsy is also a risk factor for seizure triggering [25]. Although a high number of current ASMs were not a risk factor for seizure triggering, all of our patients who had seizures more than normal after vaccination were receiving polytherapy with ASMs [24, 25]. In the study by Massoud et al., patients who had more seizures than usual after being administered the COVID vaccine were receiving polytherapy and had had epilepsy for more than 2 years [3].

Our study has limitations. Adverse events were questioned retrospectively; this may have resulted in recall bias. The caregivers answered questions on behalf of the mentally disabled patients; some adverse events such as headaches, chills, and myalgia may be overlooked. We included the patients who visited the clinic; this may have caused bias as a result of the absence of patients with serious adverse events. Our study population was younger than those in the clinical trials of the vaccine; this might have affected the adverse event profile.

In conclusion, the vaccines under consideration in our study were tolerated well by the epilepsy patients. The vaccines did not affect the monthly number of seizures of the PWE. A small number of patients had more seizures than normal after vaccination. Patients had the following common features: being on polytherapy, having epilepsy for more than 10 years, and having fever as a systemic adverse event. We think that benefits of the vaccines outweigh the slightly increased possibility of having a seizure after vaccination.

\section{Declarations}

Ethical approval The Local Ethical Committee of Ege University Medical School approved the study.

Consent to participate Written informed consent was obtained from all participants.

Competing interests The authors declare no competing interests.

\section{References}

1. Hu B, Guo H, Zhou P, Shi ZL (2021) Characteristics of SARSCoV-2 and COVID-19. Nat Rev Microbiol 19(3):141-154. https:// doi.org/10.1038/s41579-020-00459-7

2. Yan ZP, Yang M, Lai CL (2021) COVID-19 vaccines: a review of the safety and efficacy of current clinical trials. Pharmaceuticals (Basel) 14(5):406-434. https://doi.org/10.3390/ph14050406

3. Massoud F, Ahmad SF, Hassan AM, Alexander KJ, Al-Hashel J, Arabi M (2021) Safety and tolerability of the novel 2019 coronavirus disease (COVID-19) vaccines among people with epilepsy (PwE): a cross-sectional study. Seizure 92:2-9. https://doi.org/10. 1016/j.seizure.2021.08.001

4. GBD 2015 Disease and Injury Incidence and Prevalence Collaborators (2016) Global, regional, and national incidence, prevalence, and years lived with disability for 310 diseases and injuries, 1990-2015: a systematic analysis for the Global Burden of Disease Study 2015. Lancet 388(10053):1545-1602. https://doi.org/ 10.1016/S0140-6736(16)31678-6

5. Polack FP, Thomas SJ, Kitchin N et al (2020) Safety and efficacy of the BNT162b2 mRNA Covid-19 vaccine. N Engl J Med 383(27):2603-2615. https://doi.org/10.1056/NEJMoa2034577

6. Tanriover MD, Doğanay HL, Akova M et al (2021) Efficacy and safety of an inactivated whole-virion SARS-CoV-2 vaccine (CoronaVac): interim results of a double-blind, randomised, placebocontrolled, phase 3 trial in Turkey. Lancet 398(10296):213-222. https://doi.org/10.1016/S0140-6736(21)01429-X

7. Lu L, Xiong $\mathrm{W}, \mathrm{Mu} \mathrm{J}$ et al (2021) The potential neurological effect of the COVID-19 vaccines: a review. Acta Neurol Scand 144(1):3-12. https://doi.org/10.1111/ane.13417

8. Pruna D, Balestri P, Zamponi N et al (2013) Epilepsy and vaccinations: Italian guidelines. Epilepsia 54(7):13-22. https://doi. org/10.1111/epi.12306

9. Republic Of Turkey Ministry Of Health (2021) COVID-19 vaccination information platform. https://covid19asi.saglik.gov.tr/? Dil=2. Accessed 15 November 2021

10. Scheffer IE, Berkovic S, Capovilla G et al (2017) ILAE classification of the epilepsies: position paper of the ILAE Commission for Classification and Terminology. Epilepsia 58(4):512-521. https:// doi.org/10.1111/epi.13709

11. WHO Pharmacovigilance Team (2019) Causality assessment of adverse event following immunization (AEFI): user manual for the revised WHO classification. World Health Organization, Geneva 
12. Vickrey BG, Hays RD, Engel J Jr et al (1995) Outcome assessment for epilepsy surgery: the impact of measuring health-related quality of life. Ann Neurol 37(2):158-166. https://doi.org/10.1002/ ana.410370205

13. Kwan P, Arzimanoglou A, Berg AT, et al (2010) Definition of drug resistant epilepsy: consensus proposal by the ad hoc Task Force of the ILAE Commission on Therapeutic Strategies [published correction appears in Epilepsia. 2010 Sep;51(9):1922]. Epilepsia 51(6):1069-1077. https://doi.org/10.1111/j.1528-1167. 2009.02397.x

14. von Wrede R, Pukropski J, Moskau-Hartmann S, Surges R, Baumgartner T (2021) COVID-19 vaccination in patients with epilepsy: first experiences in a German tertiary epilepsy center. Epilepsy Behav 122:1-4. https://doi.org/10.1016/j.yebeh.2021.108160

15. Fonseca E, Quintana M, Lallana S et al (2020) Epilepsy in time of COVID-19: a survey-based study. Acta Neurol Scand 142(6):545554. https://doi.org/10.1111/ane.13335

16. Turkish Statistical Institute (2020) Youth in Statistics, 2020. https://data.tuik.gov.tr/Bulten/Index?p=Youth-in-Statistics-202037242\&dil=2. Accessed 15 November 2021

17. Chipaux M, Szurhaj W, Vercueil L et al (2016) Epilepsy diagnostic and treatment needs identified with a collaborative database involving tertiary centers in France. Epilepsia 57(5):757-769. https://doi.org/10.1111/epi.13368

18. Kalilani L, Sun X, Pelgrims B, Noack-Rink M, Villanueva V (2018) The epidemiology of drug-resistant epilepsy: a systematic review and meta-analysis. Epilepsia 59(12):2179-2193. https:// doi.org/10.1111/epi.14596

19. Menni C, Klaser K, May A et al (2021) Vaccine side-effects and SARS-CoV-2 infection after vaccination in users of the COVID Symptom Study app in the UK: a prospective observational study. Lancet Infect Dis 21(7):939-949. https://doi.org/10.1016/S14733099(21)00224-3
20. Borobia AM, Carcas AJ, Pérez-Olmeda M, et al (2021) Immunogenicity and reactogenicity of BNT162b2 booster in ChAdOx1-Sprimed participants (CombiVacS): a multicentre, open-label, randomised, controlled, phase 2 trial [published correction appears in Lancet. 2021 Aug 14;398(10300):582]. Lancet 398(10295):121130. https://doi.org/10.1016/S0140-6736(21)01420-3

21. Riad A, Pokorná A, Attia S, Klugarová J, Koščík M, Klugar M (2021) Prevalence of COVID-19 vaccine side effects among healthcare workers in the Czech Republic. J Clin Med 10(7):1428-1446. https://doi.org/10.3390/jcm10071428

22. International League Against Epilepsy (2021) COVID-19 vaccines and people with epilepsy. https://www.ilae.org/patient-care/ covid-19-and-epilepsy/covid-19-vaccines-and-people-with-epile psy. Accessed 15 November 2021

23. Barlow WE, Davis RL, Glasser JW et al (2001) The risk of seizures after receipt of whole-cell pertussis or measles, mumps, and rubella vaccine. N Engl J Med 345(9):656-661. https://doi.org/ 10.1056/NEJMoa003077

24. Balamurugan E, Aggarwal M, Lamba A, Dang N, Tripathi M (2013) Perceived trigger factors of seizures in persons with epilepsy. Seizure 22(9):743-747. https://doi.org/10.1016/j.seizure. 2013.05.018

25. Wassenaar M, Kasteleijn-Nolst Trenité DG, de Haan GJ, Carpay JA, Leijten FS (2014) Seizure precipitants in a community-based epilepsy cohort. J Neurol 261(4):717-724. https://doi.org/10. $1007 / \mathrm{s} 00415-014-7252-8$

Publisher's note Springer Nature remains neutral with regard to jurisdictional claims in published maps and institutional affiliations. 